Research Article

\title{
Slotted Beam-Column Energy Dissipating Connections: Applicability and Seismic Behavior
}

\author{
Xin Zhao $\mathbb{D D}^{1,2}$ and Ai Qi ${ }^{1}$ \\ ${ }^{1}$ College of Civil Engineering, Fuzhou University, Fuzhou 350108, China \\ ${ }^{2}$ College of Engineering, Fujian Jiangxia University, Fuzhou 350108, China \\ Correspondence should be addressed to Xin Zhao; 12635648@qq.com
}

Received 18 January 2021; Accepted 5 May 2021; Published 20 May 2021

Academic Editor: Melina Bosco

Copyright $(92021$ Xin Zhao and Ai Qi. This is an open access article distributed under the Creative Commons Attribution License, which permits unrestricted use, distribution, and reproduction in any medium, provided the original work is properly cited.

Energy dissipating joint can effectively strengthen the connection of prefabricated buildings. In the present study, a new slotted mild steel damper was installed at the beam end of the prefabricated structure to form as the energy-dissipating joint of the beamcolumn. By using ABAQUS software, a finite element (FE) analysis was conducted for the single-story-and-span of the singleframe structure with a slotted damper as energy-dissipating joint. The result shows that the damper was the first to yield in the structure and performed well in energy dissipation, indicating its reasonable design of structure and connection. The energy dissipation mainly occurred at the flange of the variable cross sections, between which beam-ribbed webs ensured the required bearing capacity and stiffness and provided a reliable connection. The hysteretic curves were obtained by analyzing the mechanical properties of the slotted damper under pure bending and pure shearing. In the OpenSees platform, the Steel02 Material model and the twoNodeLink element were used to fit the hysteretic curves; this method was employed for the parametric simulation of the slotted energy dissipation. The dynamic characteristics and seismic response of the controlled structure with slotted energy dissipating joint were also analyzed and compared with those of the uncontrolled structure in the OpenSees platform. The results show that the period of the controlled structure was prolonged and the top story acceleration decreased, indicating its effect in reducing seismic response. The shear-dependent seismic reduction ratio was about $35 \%$, while the drift-dependent seismic reduction ratio was about $10 \%$. The seismic performance of bottom story was better than that of the top story, and the damper has good energy dissipation performance in the bending direction. Some detailed design criteria are put forward and consequences for design on the basis of the performed simulations are shown.

\section{Introduction}

Previous earthquakes have shown that the damage of prefabricated concrete structures is concentrated at the connection of joints [1]. The connections of beam-column joints, slabs, and shear walls are the critic part that affects the overall seismic performance of the prefabricated structure, requiring sufficient strength, stiffness, and ductility $[2,3]$. Researchers have tried to explore a superior connection method for prefabricated buildings. By using the isolation or energy dissipation technique [4], they placed the energy dissipating brace, coupling beam, splicing component of slab or shear wall, and the damper at beam-column joint to (1) increase the ductility of the joint or the component itself and thereby improve the reliability of connection and to (2) control and reduce the seismic response of the structure by utilizing the energy dissipation of the joint or the component itself. The energy dissipating joint of the beam-column has attracted increasing attention due to its effect in improving the connection reliability of prefabricated building [5]. In previous studies, the energy dissipation devices as the beam-column energy dissipating joints can be divided into low-yield-point metal damper [3-6], friction damper [7, 8], viscoelastic damper [9], and composite damper [10].

In terms of the low-yield-point metal damper, some researchers proposed that different shapes of silts should be set at appropriate locations of the metal damper to improve its performance. In 2005, Korkmaz and Tankut [1] proposed a metal damper consisting of welded $\mathrm{H}$-beam and 
T-joint with slits on the flange and conducted a beamcolumn joint test on specimens with different rib widths and slit lengths. In 2008, Chan and Albermani [11] conducted a hysteretic test on the steel plate damper with slits of different lengths mounted on the herringbone-shaped brace. In 2013, Saffari et al. [12] proposed a slit damper which was placed on the lower flange of the beam to strengthen the strength and ductility of the joint. In 2015, Hedayat et al. [13] studied 749 working conditions of slit dampers as energy dissipating wall limbs and regressed the results, thereby proposing a calculation formula for predicting the critic points of the hysteretic curve. In 2015, Lee et al. [14] proposed a steel damper with strip-shaped and hourglass-shaped strips. Studies on the slit metal dampers of various shapes proved that a reasonably designed slit metal damper has good hysteretic energy dissipation and simple structure and is easy to be parameterized and replaced. Additionally, it has the advantages of low manufacturing cost, insensitivity to ambient temperature, and high reliability in a long-term period [15]. The metal slotted damper in the above studies can be installed in the brace as the energy dissipating component of the brace. Also, it can be installed between the main beam of two stories as the energy dissipating wall limb. Moreover, it can be installed below the beam-column joint as the support of the main beam haunch. However, it is rarely installed at the beam end as a part of the main beam to form as the beamcolumn energy dissipating joint.

In terms of research on structural seismic reduction, in 2017, Lee and Kim [3] proposed a box-shaped slotted steel plate damper and used it for structural seismic reinforcement. Their results showed that this damper could obtain large energy dissipation with a small size. Given the ultimate state of the target performance, the damper installed by the capability spectrum-based method could effectively suppress the interstory drift. However, there is limited research on the seismic performance of the structure with beam-column energy dissipating joints.

In order to improve the seismic reliability of the beamcolumn joints of the prefabricated structure, a slit damper is required to be placed at the beam-column joint as its energy dissipating component. Additionally, the damper must have sufficient initial stiffness and can reach the plastic state with energy dissipating at appropriate drift. The safety performance of the main beam should also be ensured after the damper yields. Thus, the damper should not only meet the standards of the prefabricated buildings but also be easy to install and replace. Therefore, the present study mainly concerns the problems of how to design a slotted damper placed at the end of the main beam and suitable for forming the energy dissipating joint of the fabricated beam-column and how to ensure that the initial stiffness, yield drift, and post-yield stiffness can meet the requirements of the structure to reduce its seismic response. Also, this study aims to find a numerical simulation method to accurately simulate the restoring force model and mechanical properties and thereby analyze the dynamic characteristics and seismic reduction effect of the controlled structure with energy dissipating joint.

\section{Prosperities of the Slotted Energy- Dissipating Joint}

2.1. Structure of the Slotted Damper. Considering that the metal damper to form as the beam-column energy dissipating joint would be placed at the end of the frame beam, it is required that it (1) has sufficient initial stiffness to ensure that the structure is safe and reliable under normal use conditions; (2) has small yield drift and post-yield stiffness to ensure that under the designed target ground motion, it can reach the state of energy dissipation and hysteresis to absorb seismic energy; (3) its maximum bearing capacity meets the requirement of the structure under large earthquakes to prevent failure and thereby to ensure the safety during and after the earthquake; (4) has good energy dissipation; and (5) has reliable connection. The author proposed a slotted lowyield-point steel damper consisting of variable-section flange and beam-ribbed slotted web. Both sides of the damper are fixed by two connecting plates with preembedded snails and anchor plate. The structure of the damper is shown in Figure 1.

Since the thickness of the outer flange is thinner, by controlling the thickness of the flange, the damper can be ensured to yield fast with small deformations and the deformation and yield of the damper mostly occur on the flange. The web is slotted to form a beam-ribbed web, and its yield force and bearing capacity can be controlled by the quantity, width, and thickness of the rib. The two sides of the damper are connected by double-joint plates with highstrength snail and anchor plate which are preembedded in the beam-column core area, and the two connecting plates are welded around the outer ring of the small plate to ensure the reliability of the connection.

2.2. Performance of the Joint. A certain span of a bottom story from a typical frame structure building with a bay length of $6 \mathrm{~m}$ and a bottom story height of $3.3 \mathrm{~m}$ was taken as the research object. A slotted damper was installed at the end of the beam and a horizontal cyclic load was applied thereto. Strength grade C35 was applied for the concrete and HRB400 was adopted for the steel bar. The load transmitted from the superstructure to the bottom column was $150 \mathrm{kN}$. The dimensions of the frame model and damper are shown in Figure 2, and the reinforcement of the beam-column is shown in Figure 3. All steel bars are the third grade in Chinese code. PLY160 was adopted for the damper as shown in Figure 4 and its material performance is described in the literature [16]. The hysteretic loading system is shown in Figure 5.

Through the finite element (FE) analysis, the hysteretic curves and skeleton curves of the frame structure were obtained, as shown in Figure 6.

It can be seen from the hysteretic and the skeleton curves that the hysteretic loop is plump which indicates a good energy dissipation, and the structure reached the plastic state at the horizontal drift of $3.992 \mathrm{~mm}$. At this point, the stress states of the damper, steel bar, and concrete were observed as shown in Figure 7. 


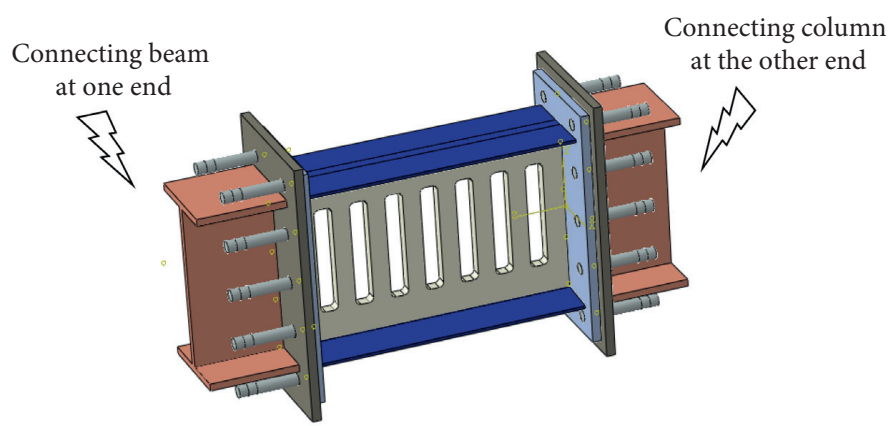

(a)

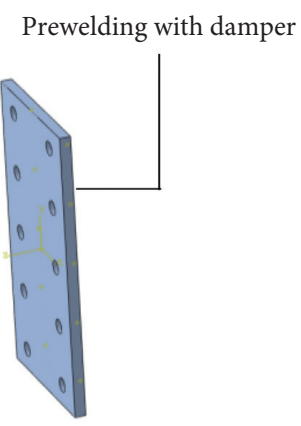

(b)

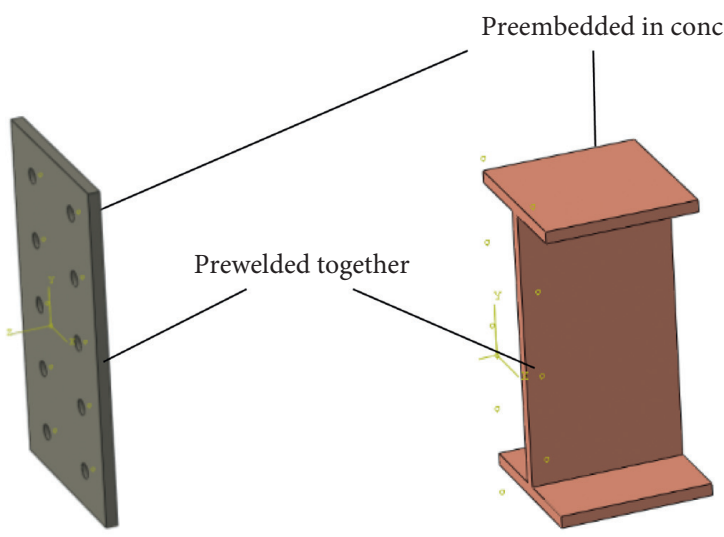

(c)

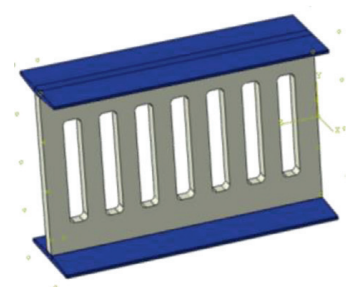

(f)

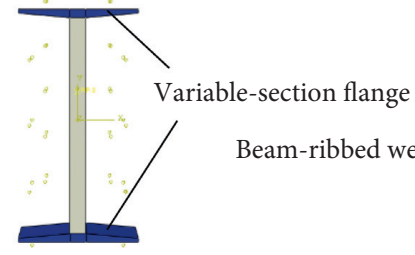

(g)

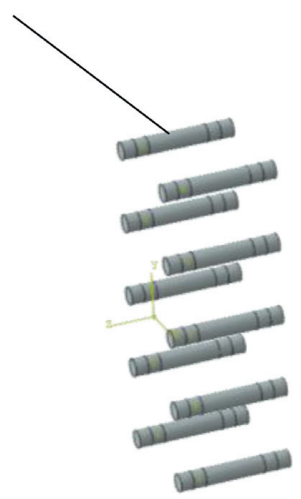

(e)

Figure 1: Structure of the slotted damper. (a) Damper and its connection, (b) connecting plate 1, (c) connecting plate 2, (d) anchor plate, (e) high-strength snails, (f) damper, (g) front view of damper, and (h) side view of damper.

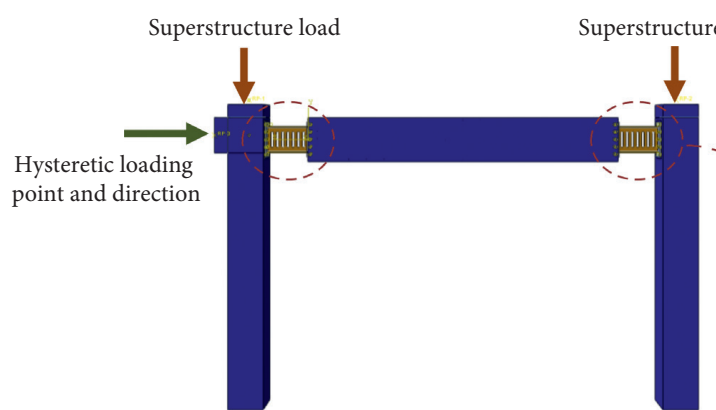

(a)

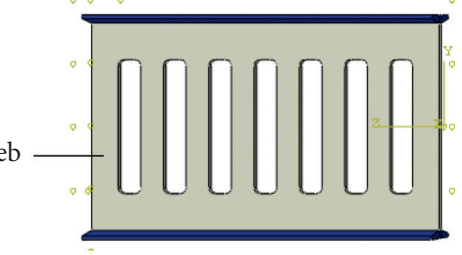

(h)

Figure 2: Frame model (mm).

The damper yielded first in the thinner part of the outer flange, and the part of the damper with higher stress was concentrated on the flange, while most steel bar and concrete were still under low stress. The maximum stress of the steel bar appeared at the bottom of the column, which was $80 \mathrm{~N} / \mathrm{mm}, 22.9 \%$ of the yield strength and $20 \%$ of the ultimate strength. The maximum stress of the concrete appeared inside of the upper column, which was $18 \mathrm{~N} / \mathrm{mm}, 78 \%$ of the cracking stress and $62 \%$ of the ultimate strength.

Figure 8 shows the stress nephograms at the horizontal drift of $60 \mathrm{~mm}$. 


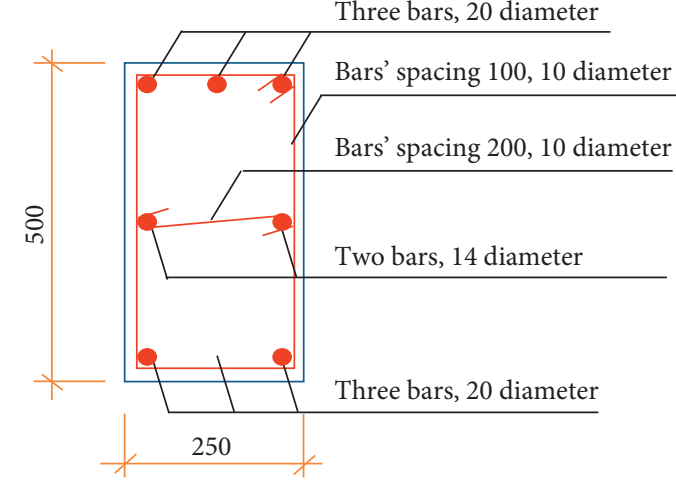

(a)

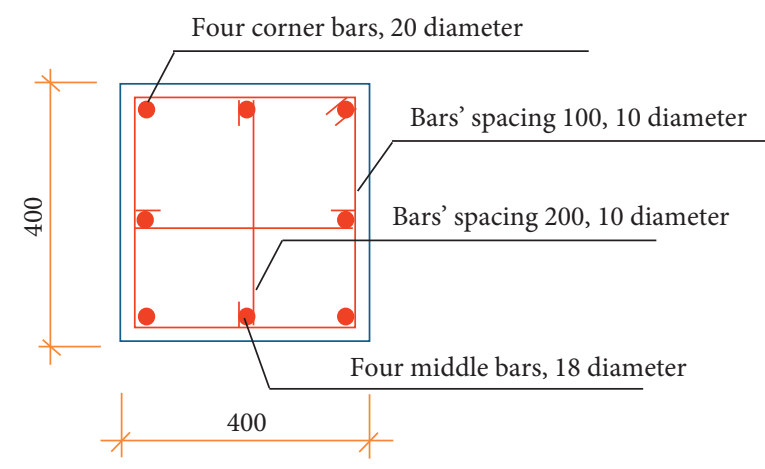

(b)

Figure 3: Reinforcement of the beam-column. (a) Reinforcement of the beam. (b) Reinforcement of the column.

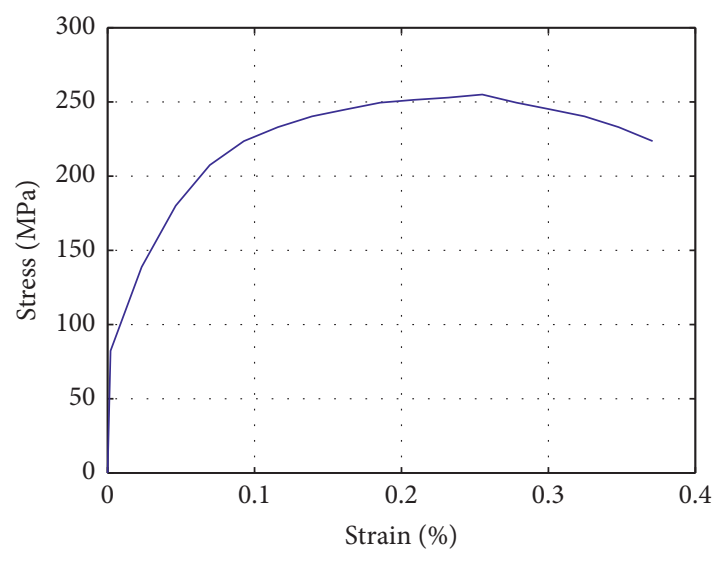

Figure 4: YLP100 stress-strain curve.

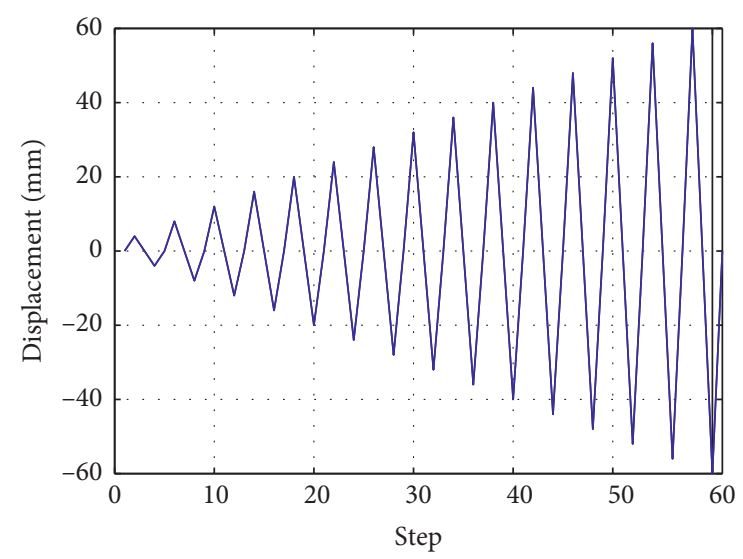

Figure 5: Loading system.

When the horizontal drift was loaded to $60 \mathrm{~mm}$, the loading was stopped. It can be seen from the stress nephograms that the deformation of the structure was concentrated on the damper. The energy dissipation of the damper protected the main structure from damage. The yielding of the steel bar was only found at the bottom of the column. The yielding part of the damper was mostly in the flange region, indicating that the flange is the main energy

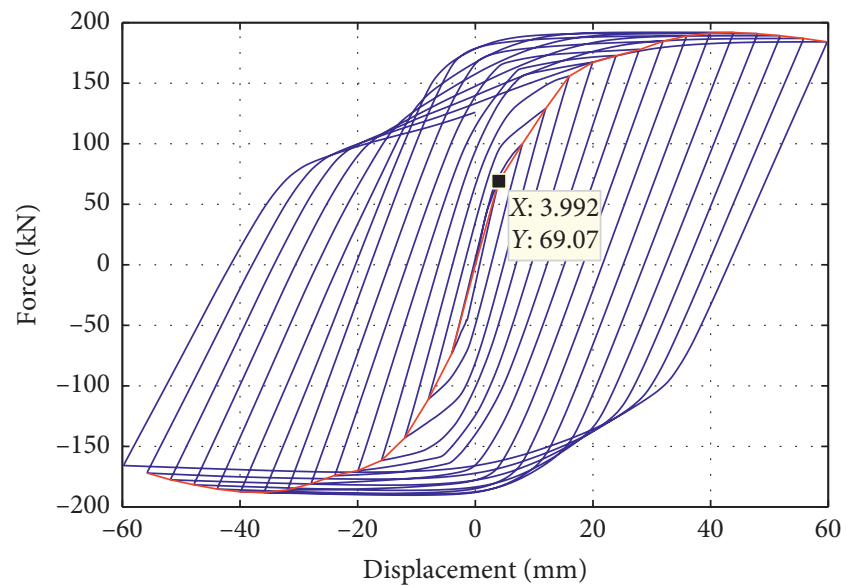

Figure 6: Hysteretic curves and skeleton curves of the frame structure.

dissipating part of the damper. The beam rib of the web did not yield, ensuring the bearing capacity of the damper.

\section{Modeling of Slotted Joint in OpenSees}

ABAQUS software has advantages in finely and visually creating geometry models, setting contact, generating mesh, and promoting postprocessing visualization. It is thus suitable for building solid elements for slotted joints to achieve fine simulation. The open-source OpenSees platform is rich in nonlinear elements, material database, and algorithms developed for strong nonlinear analysis to simulate the seismic response of large structures, indicating its advantages over ABAQUS in terms of seismic performance analysis of structures. Therefore, it is necessary to find an effective approach to simulating slotted joints in the OpenSees platform.

3.1. Connection Element and Restoring Force Model. In OpenSees, twoNodeLink is used to simulate the connection element of zero-length or non-zero-length. The uniaxial stress-strain material relationship can be used as the mechanical model of the connection element, and the 


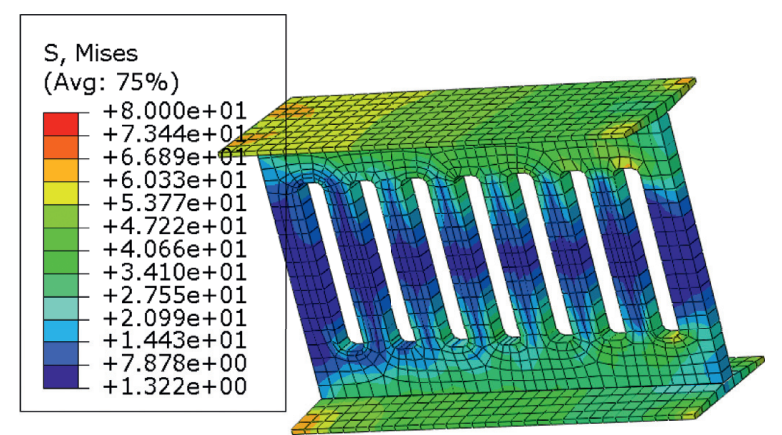

(a)

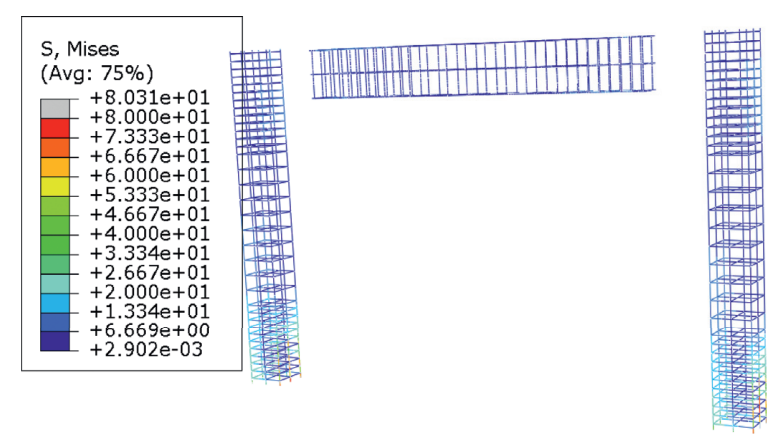

(b)
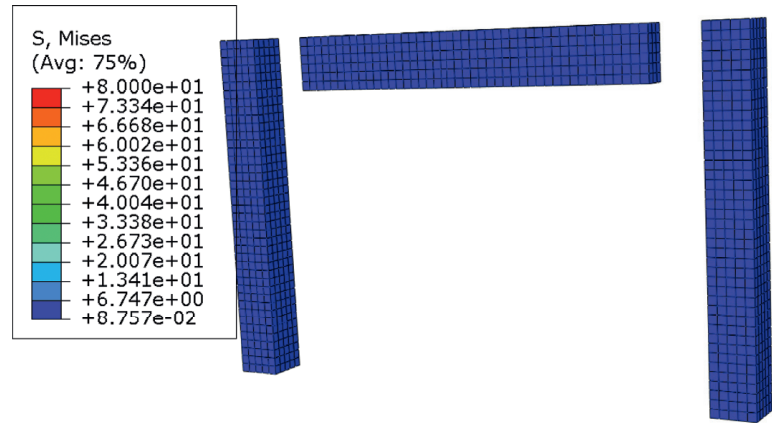

(c)

Figure 7: Stress nephograms of the damper, steel bar, and concrete at the horizontal drift of $3.9 \mathrm{~mm}$. (a) Stress nephogram of the damper. (b) Stress nephogram of the steel bar. (c) Stress nephogram of the concrete.
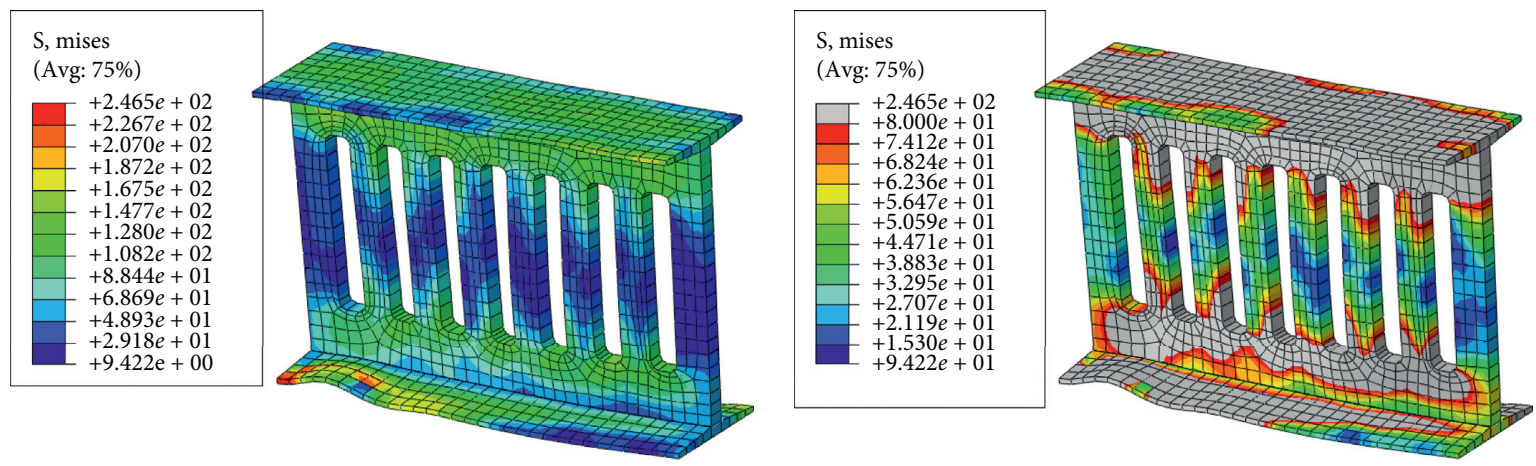

(a)

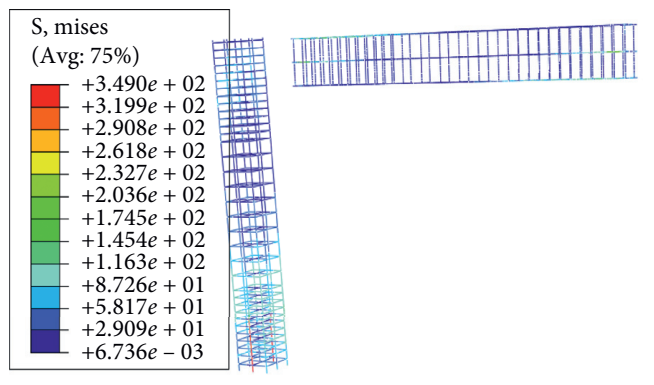

(b)
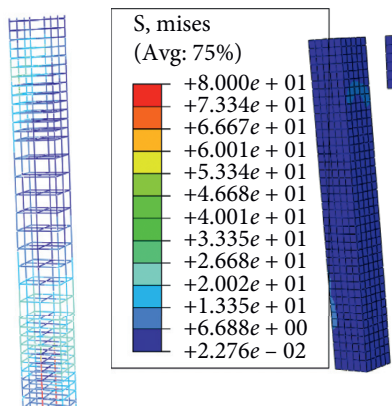

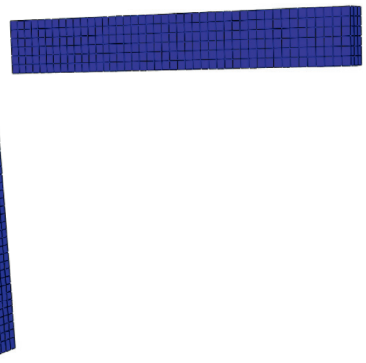

(c)

FiguRE 8: Stress nephograms of the damper, steel bar, and concrete at the horizontal drift of $60 \mathrm{~mm}$. (a) Stress nephogram of the damper. (b) Stress nephogram of the steel bar. (c) Stress nephogram of the concrete. 
force-drift relationship can be used as the material model. Figure 9 shows its mechanical diagram, where " $\mathrm{u}_{1}, \mathrm{q}_{1}$," " $\mathrm{u}_{2}$, $\mathrm{q}_{2}$," and " $\mathrm{u}_{3}, \mathrm{q}_{3}$," respectively, represent the relationship between strain and stress, or drift and force of the element in the axial direction, bending direction, and torsion direction. The directions can be coupled or uncoupled to each other.

In OpenSees, Steel02 Material is used to simulate the isotropic strain hardening uniaxial Giuffrè-Menegotto-Pin to steel material [17]. The constitutive model is applicable to the parameter input of the restoring force model with known yield force, initial stiffness and post-yield stiffness, and the hysteretic curves can be adjusted through shape parameters.

The hysteretic curves of the slotted damper in shear direction and bending direction were, respectively, fitted by Steel02 Material. The relationship of force and drift was then given to twoNodeLink in these two directions as the mechanical model of the slotted damper.

3.2. Parameterized Simulation of the Damper. FE simulation and analysis were performed in ABAQUS to obtain the hysteretic curves of the slotted damper in shear and bending directions. The analysis model and loading system are shown in Figure 10.

Steel02 Material has a total of 12 parameters. By adjusting the parameters, the structure of FE simulation was fitted to the hysteretic curves in bending and shearing directions, as shown in Figure 11. The values of the parameters are shown in Table 1.

Through the comparison of the hysteretic curves of ABAQUS FE analysis results and of parameter fitting by inputting and adjusting parameters in OpenSees, it can be found that the two matched well when directly inputting the yield force and initial stiffness. The bearing capacity, unloading stiffness, and cumulative energy dissipation can be matched well by adjusting the shape parameters of the hysteretic curves. Since Steel02 is a bilinear model, the damper in the FE simulation showed slight stiffness and strength degradation, and the post-yield stiffness was shown in curve shape which cannot be fully fitted in the Steel02 model. In general, a good simulation can be obtained through OpenSees by using the Steel02 Material model to simulate the hysteretic characteristics of the slotted damper in bending and shear directions.

3.3. Simulation Verification. In the OpenSees platform, the single-story-and-span frame model of the ABAQUS FE analysis in Section 1.2 is established, as shown in Figure 12. The method in Section 2.2 was used to simulate the damper with the same parameters. By comparison, the hysteretic curves and skeleton curves of ABAQUS and OpenSees are shown in Figure 13.

Figure 14 shows that, in terms of the hysteretic curves, the stiffness in OpenSees degrades faster than that in ABAQUS. Therefore, the hysteretic curves in OpenSees had a more significant pinching effect. In terms of the skeleton curve, the two agree well in initial stiffness, yield point, and bearing capacity. The effective simulation of

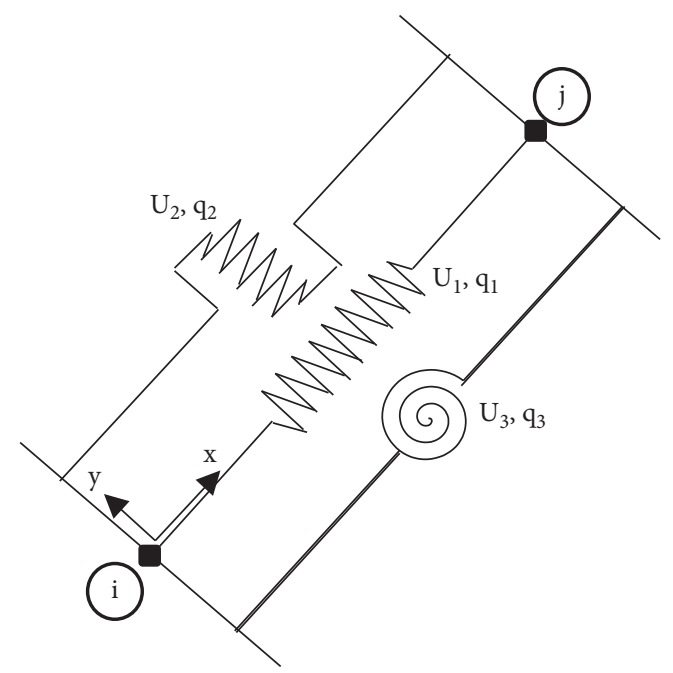

FIgURE 9: Schematic diagram of twoNodeLink element.

slotted dampers is the key point to realize the seismic research of the structure on the platform of OpenSees.

\section{Seismic Response Analysis of the Controlled Structure}

The above simulation method was used to carry out the numerical simulation, dynamic characteristic analysis, and seismic response analysis to the structure with slotted energy dissipating joint in the OpenSees platform.

4.1. Establishment of the Structural Analysis Model and Selection of the Elements. A single-span six-story reinforced concrete structure with a span of $6 \mathrm{~m}$ in both directions and a story height of $3 \mathrm{~m}$ was designed as the uncontrolled structure. The frame beam had a section of $250 \times 500 \mathrm{~mm}^{2}$, while the frame columns of stories 1 and 2 had a section of $700 \times 700 \mathrm{~mm}^{2}$ and those of stories 3-6 had a section of $600 \times 600 \mathrm{~mm}^{2}$. The concrete grade C40 was used for the concrete, and HRB400 was used for the steel bar. The metal damper was placed at each beam end of each story of the uncontrolled structure to be as the controlled structure. The FE model, as shown in Figure 14, was established using OpenSees for numerical analysis. The reinforced concrete beam-column was simulated by the Force-Based BeamColumn Element, with 4 integration points set in each element. With the section Aggregator command, the characteristics of the section fiber were given in axial and shear directions to define the section size and reinforcement of the reinforced concrete beam-column. In the directions of bending and torsion, the bending and torsional stiffness values of the reinforced concrete beam-column were defined by calculation. The damper was simulated by the twoNodeLink element. With the Steel02 constitutive model, two different constitutive properties that can respectively represent the hysteretic characteristics of the shear and the bending directions were defined and given twoNodeLink element. The two directions are coupled to each other. 


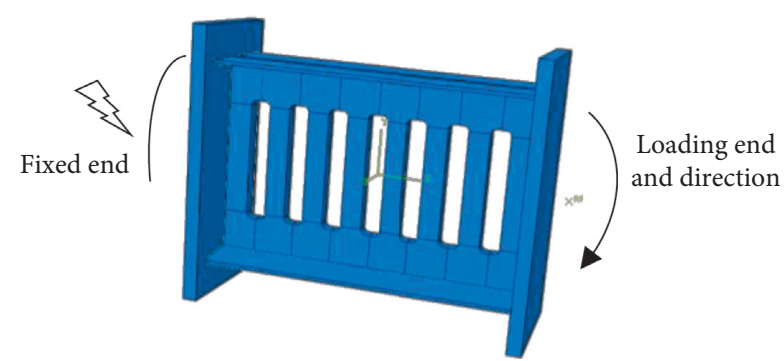

(a)

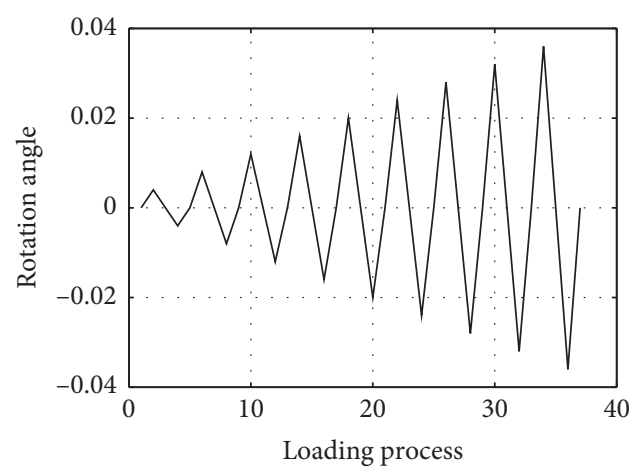

(c)

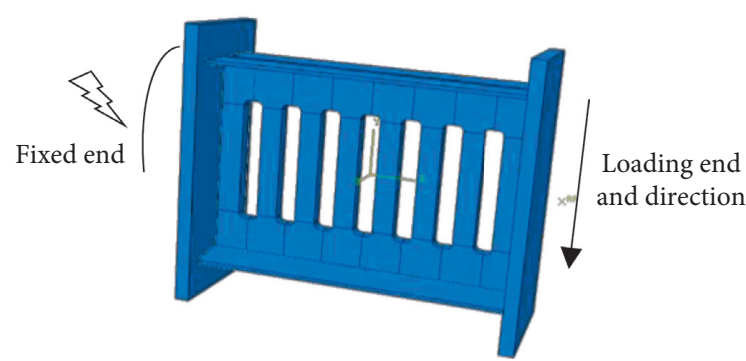

(b)

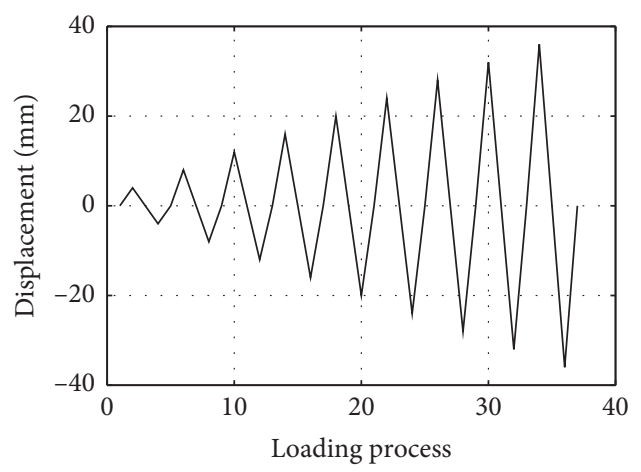

(d)

FIGURe 10: Analysis model and loading system. (a) Analysis model of loading in bending direction. (b) Analysis model of loading in shear direction. (c) Loading system in bending direction. (d) Loading system in shear direction.

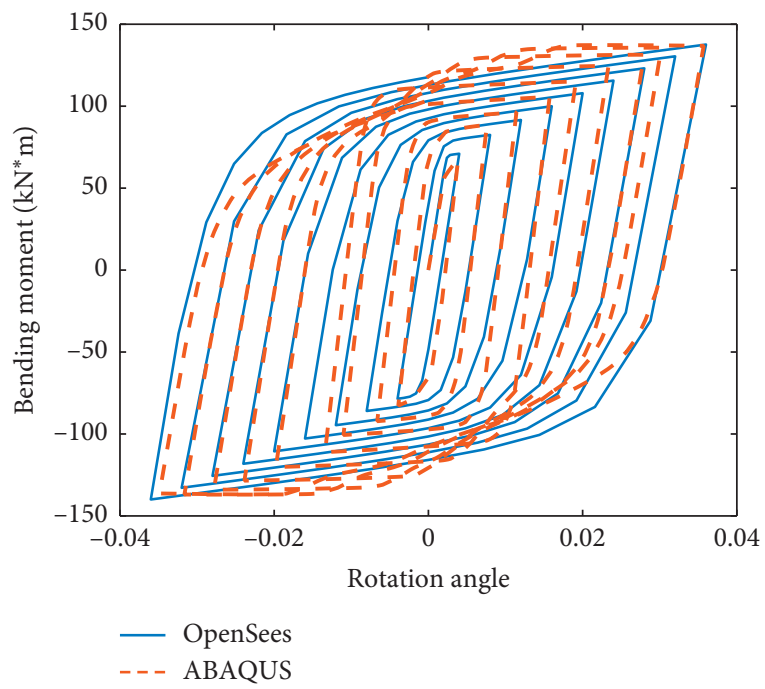

(a)

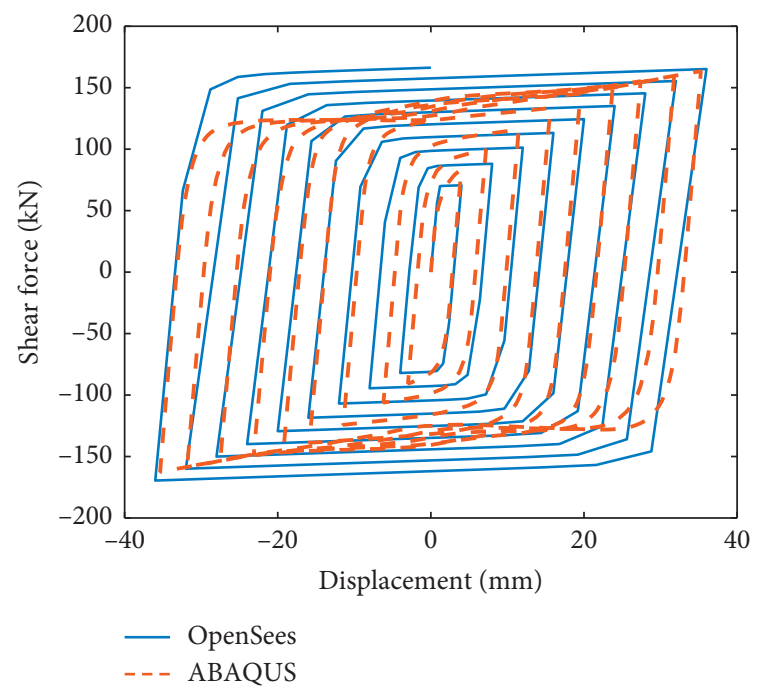

(b)

FIGURE 11: Comparison of ABAQUS FE simulation results and OPENSEES parameters fitting. (a) Hysteretic curves of loading in bending direction. (b) Hysteretic curves of loading in shear direction.

4.2. Modal Analysis. Using the OpenSees platform and its model, the modal analysis was performed, and the characteristic period of the uncontrolled structure was obtained as $0.631 \mathrm{~s}$. In order to ensure the accuracy of the model, another uncontrolled structure model was established by Etabs software for modal verification. The error was $0.6 \%$, indicating that the OpenSees analysis model is correct. The characteristic period of the controlled structure was $0.772 \mathrm{~s}$, indicating that the placement of the damper extends the period of the structure.

4.3. Acceleration Analysis. Under the condition of the rare earthquake and with a basic acceleration of $0.15 \mathrm{~g}$, El Centro wave, Taft wave, and Tongan artificial wave were input into the uncontrolled and the controlled structures to analyze and compare their seismic responses. Figure 15 shows the 
TABLE 1: Significance and value of parameters.

\begin{tabular}{|c|c|c|c|c|c|c|}
\hline Parameter & Fy & $\mathrm{E}$ & Bsh & R0 & $\mathrm{cR} 1$ & cR2 \\
\hline Significant & Yield strength & Elastic modulus & Strain-hardening ratio & \multicolumn{3}{|c|}{$\begin{array}{l}\text { Parameter to control the } \\
\text { transition from elastic to } \\
\text { plastic branches }\end{array}$} \\
\hline Value of bending direction & 70 & $3 e+04$ & 0.02 & 20 & 0.92 & 1 \\
\hline Value of shear direction & 70 & $7 e+04$ & 0.003 & 20 & 0.8 & 1 \\
\hline Parameter & a1 & $\mathrm{a} 2$ & a3 & $\mathrm{a} 4$ & $\begin{array}{c}\text { Wei } \\
\text { V }\end{array}$ & $\begin{array}{l}\text { nsity } \\
\text { ric }\end{array}$ \\
\hline Significant & \multicolumn{2}{|c|}{ Isotropic hardening parameter } & \multicolumn{2}{|c|}{ Isotropic hardening parameter } & $\begin{array}{c}\text { weig } \\
\text { of }\end{array}$ & $\begin{array}{l}\text { sity } \\
\text { ial }\end{array}$ \\
\hline Value of bending direction & 0.5 & 9 & 0.5 & 9 & 0 & \\
\hline Value of shear direction & 0.1 & 1.35 & 0.1 & 1.35 & 0 & \\
\hline
\end{tabular}

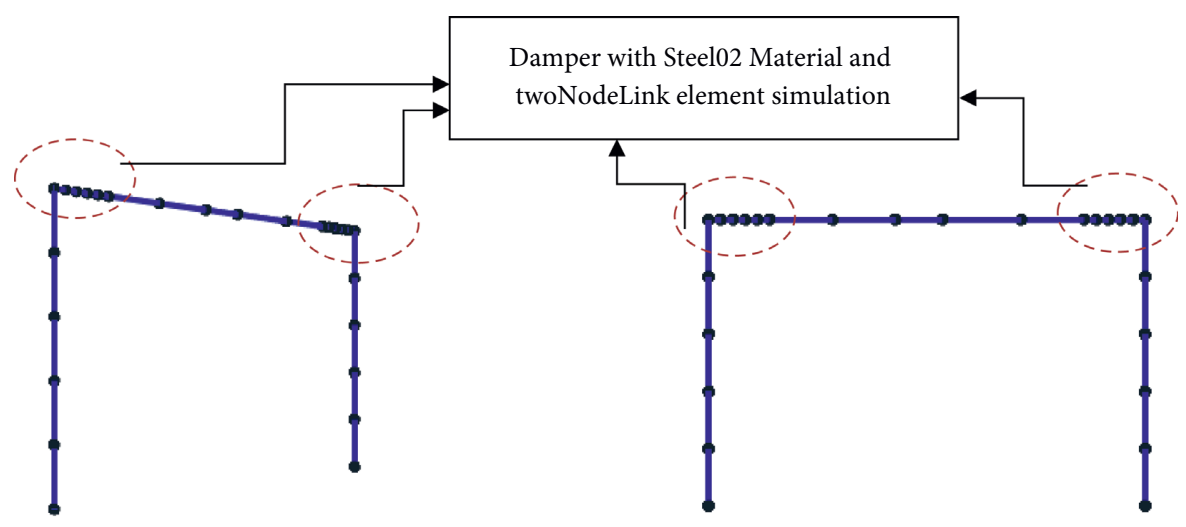

Figure 12: Single-story-and-span frame model in OpenSees.

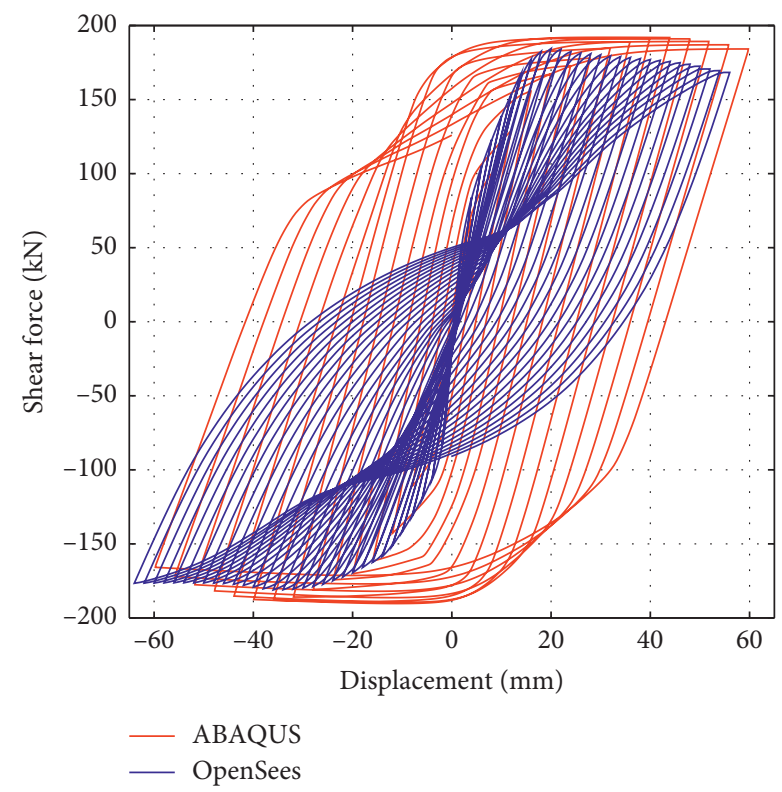

(a)

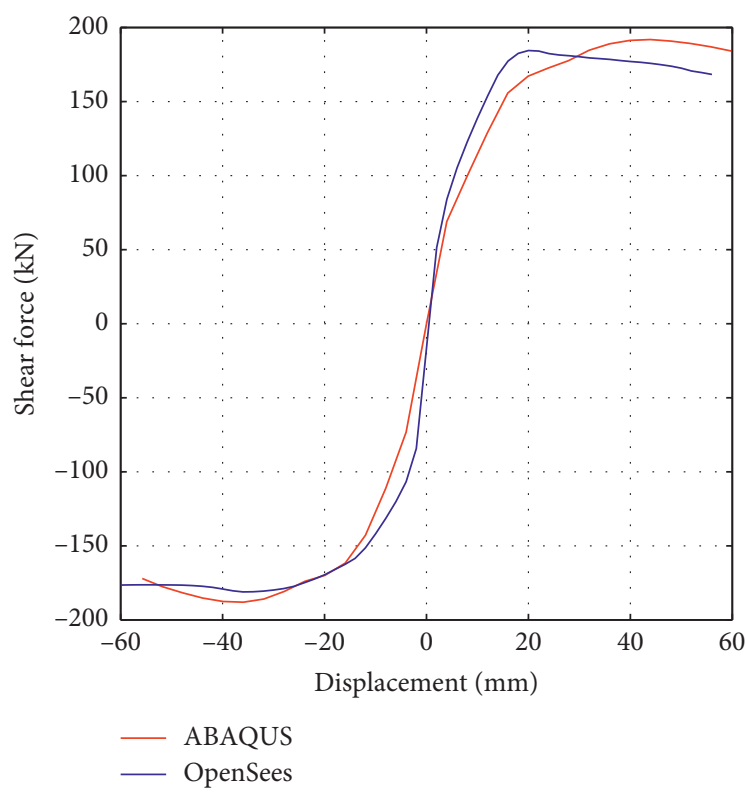

(b)

FIGURE 13: Hysteretic curves and skeleton curves.

top-story acceleration time-history response and the acceleration value at the peak point of the uncontrolled and controlled structures under three seismic waves.
"Structure-U" represents the uncontrolled structure, "Structure-C" represents the controlled structure, "Peak-U" denotes the peak acceleration of the uncontrolled structure, 


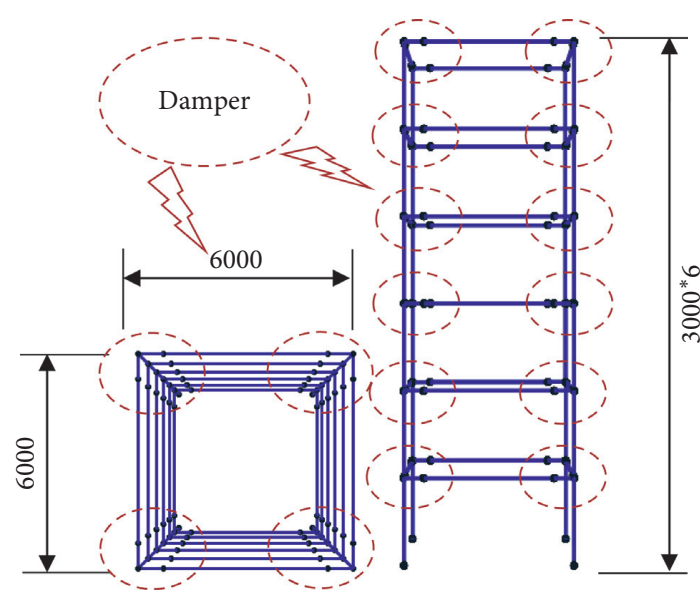

(a)

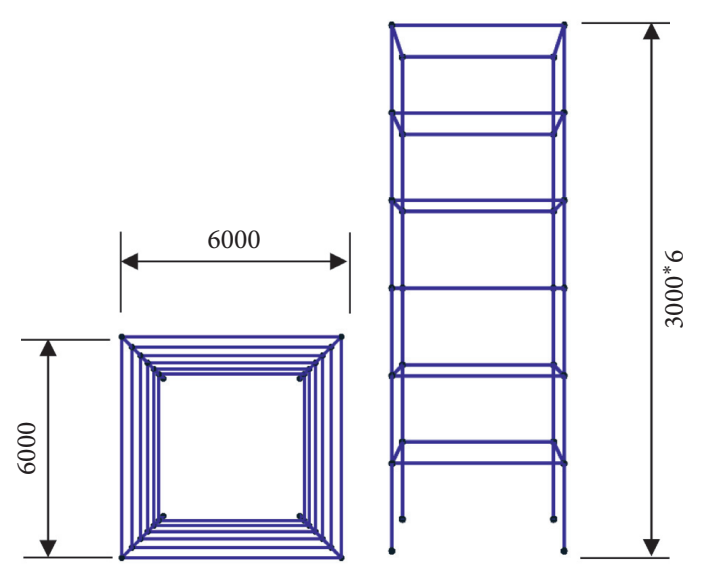

(b)

Figure 14: Controlled structure model (mm). (a) Controlled structure. (b) Uncontrolled structure.

and "Peak-C" represents the peak acceleration of the controlled structure. The seismic reduction ratios of the top story under El Centro, Tongan, and Taft waves were $27.1 \%$,
$-1.6 \%$, and $17.9 \%$, respectively, and the average seismic reduction ratio was $14.4 \%$. The formula used to calculate seismic reduction ratio is

$$
\text { seismic reduction ratio }=\frac{\text { values of uncontrolled structure }- \text { values of controlled structure }}{\text { values of uncontrolled structure }} \times 100 \% \text {. }
$$

This indicates that the energy dissipating joint has a suppression effect on the acceleration of the structure.

4.4. Shear Force and Drift Analysis. The story shear force and its seismic reduction ratio of the uncontrolled and the controlled structures are shown in Figure 16. The story drift and its seismic reduction ratio are shown in Figure 17. The seismic reduction ratio values of each story are shown in Tables 2 and 3 .

The analysis shows that the seismic reduction ratio of the shear force was between $23.5 \%$ and $41.7 \%$, and the average ratio was $34.9 \%$. The drift seismic reduction ratio was between $-31.9 \%$ and $37.4 \%$, with an average ratio of $10.4 \%$, and the negative seismic reduction ratio only appeared at story 6 under Taft wave and stories 2 and 6 under Tongan wave. These results indicate that the energy dissipating joint can effectively reduce the story shear of the structure, while the seismic reduction effect of the shear force is better than that of the drift. The average shear seismic reduction ratio of the first to the third story was $38.0 \%$, while the average drift seismic reduction ratio was $21.2 \%$. The average shear seismic reduction ratio of the fourth to sixth stories was $31.8 \%$, and the average drift seismic reduction ratio was $-0.4 \%$. This result indicates that the energy dissipating joint has a better control effect on the structural seismic response of the lower story than the upper story.

4.5. Energy Dissipation Analysis of the Damper. Under three seismic waves, the shear force and bending moment of the damper at the left end of the top-story uniaxial frame beam and the relationship of their corresponding deformations were observed. In the shear direction, the damper was still in the elastic phase and did not begin to dissipate energy. In the bending direction, the energy dissipating hysteretic loop of the damper is plump, as shown in Figure 18.

\section{Design Suggestion}

5.1. Response Spectrum Analysis. On the basis of the performed simulations above, the pseudoacceleration response spectrum and displacement response spectrum of the three waves were obtained by normalizing the peak value, and the effect of additional damping was considered. The response value of the uncontrolled structure and the controlled structure can be found, as shown in Figures 19 and 20.

The dotted line represents the response spectrum curve without considering additional damping, and the solid line represents the response spectrum curve considering additional damping; $\bigcirc$ and ${ }^{*}$ represent the uncontrolled and controlled structure response of this case, respectively. In the pseudoacceleration response spectrum, after reaching the peak value, the period of the controlled structure increases, and the acceleration response decreases along the response spectrum curve; the hysteretic energy dissipation of the damper provides additional damping to the structure, and the additional damping can furtherly reduce the response of the structure. In the displacement response spectrum, the displacement increases correspondingly as the period increased, but it is restrained to a certain extent while considering the additional damping. Considering these two 


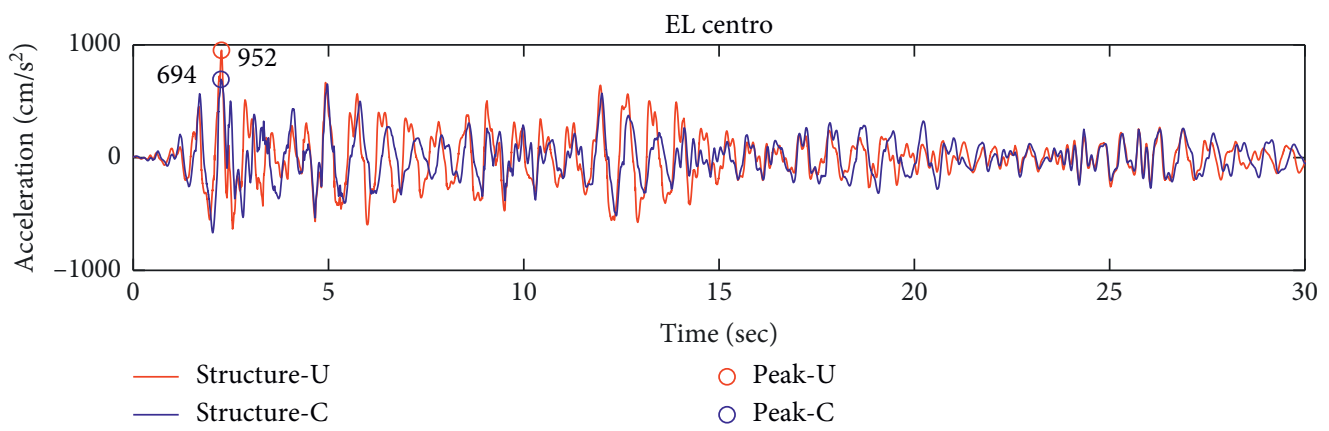

(a)

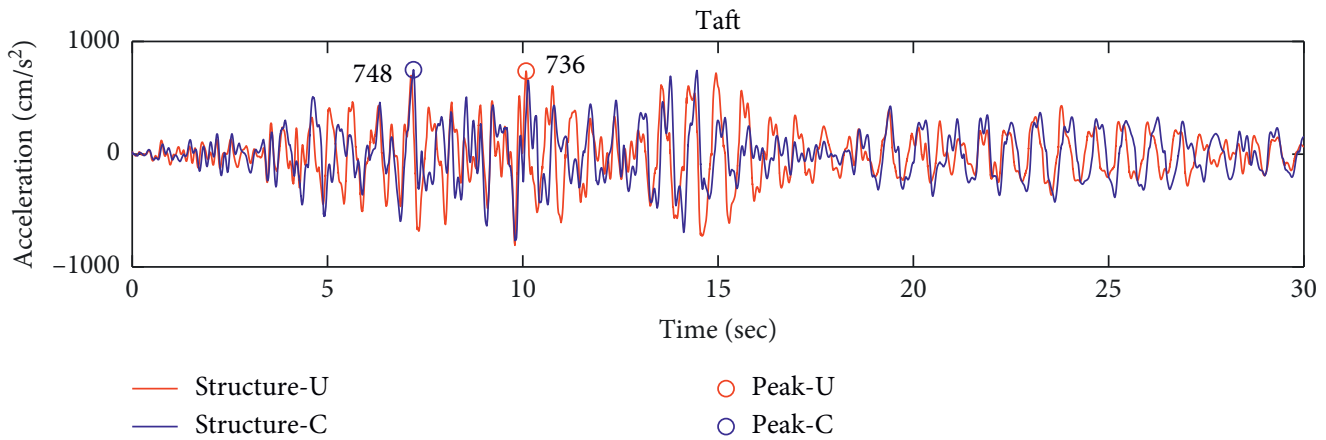

(b)

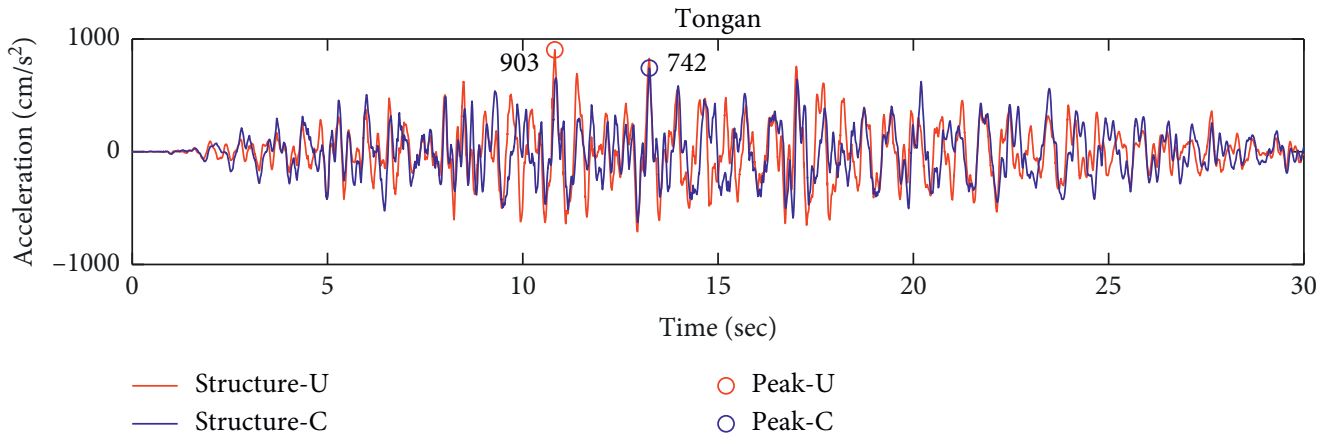

(c)

FIGURE 15: Time-history response of acceleration.

factors, the displacement ratio of the controlled structure is likely to be reduced compared to the controlled condition, but the reduced ratio is not as large as the acceleration response. Therefore, the seismic reduction effect of story shear is better than the effect of story drift. When the structure is subjected to strong earthquakes, the dampers would further yield and consume energy; the period of the controlled structure further increases, and the acceleration and layer shear control effects would become better.

5.2. Suggestion for the Design. Dampers are set at the beam ends to form energy dissipating connections to reduce structural seismic response. On the one hand, the dampers change the stiffness of the frame beam, thus changing the stiffness characteristics of the structure; on the other hand, due to the plastic deformation of the dampers, the damping characteristic of the structure is changed. According to the analysis of the response spectrum above, the following suggestions are put forward for the structural design:

(1) From the analysis of seismic reduction rate and response spectrum, it can be seen that the seismic reduction effect of acceleration and shear is obvious for the energy dissipation joint structure; thus, the acceleration seismic reduction rate and shear seismic reduction rate can be used as the main design index. Particularly for building with a short natural period, this index can be set to more than $20 \%$ as a design criterion for this type of structure.

(2) The displacement control effect is not as good as the shear force, but the corresponding design standard can be appropriately relaxed. The reason is that the damper added to the beam end needs to have a small stiffness to yield and dissipate energy first in an earthquake. Since the floor displacement is mostly 


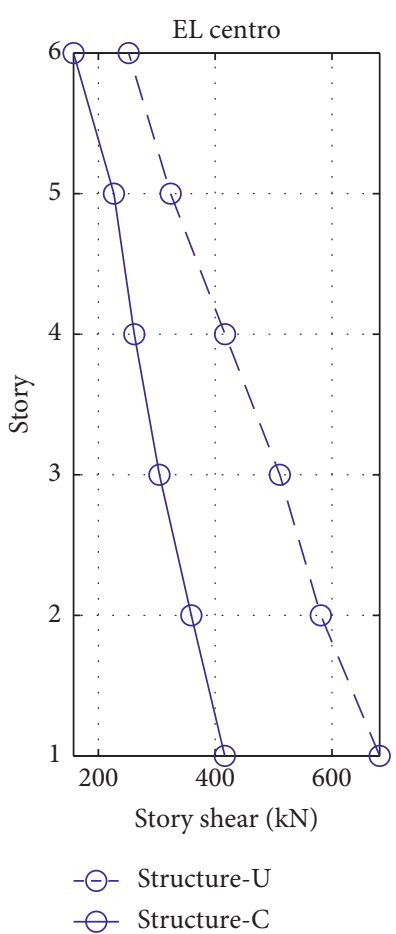

(a)

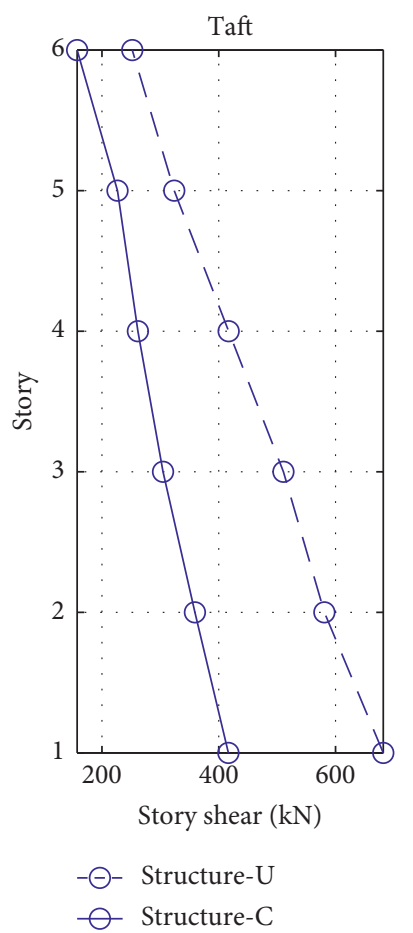

(b)

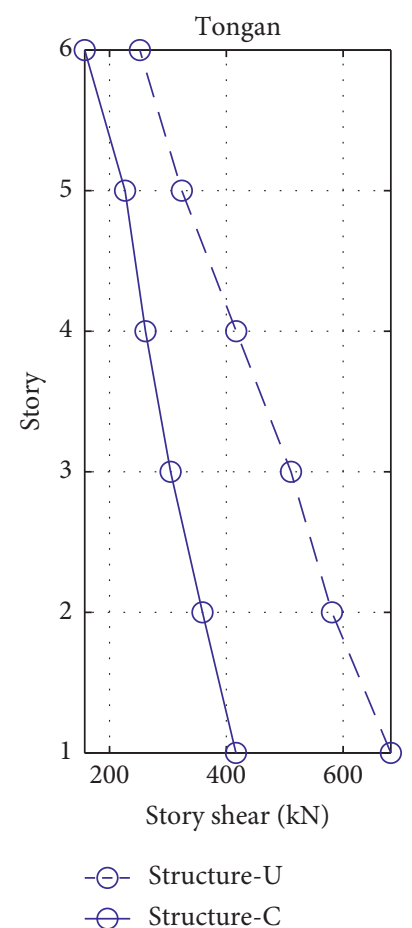

(c)

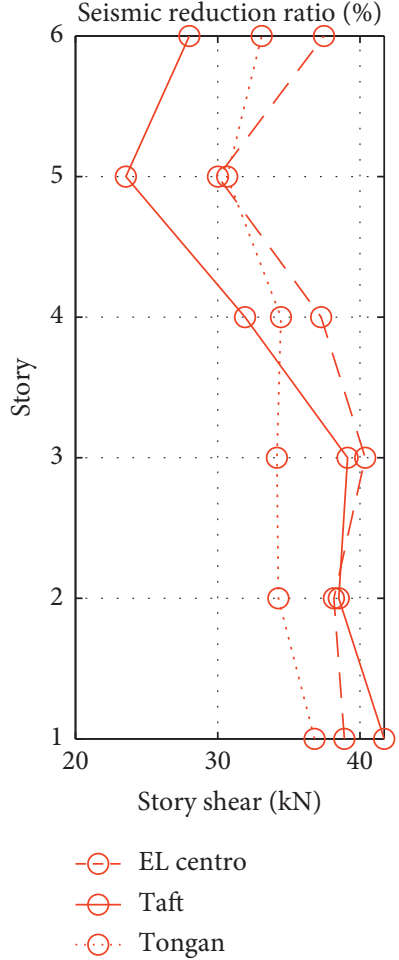

(d)

FIGURE 16: Story shear and its seismic reduction ratio.

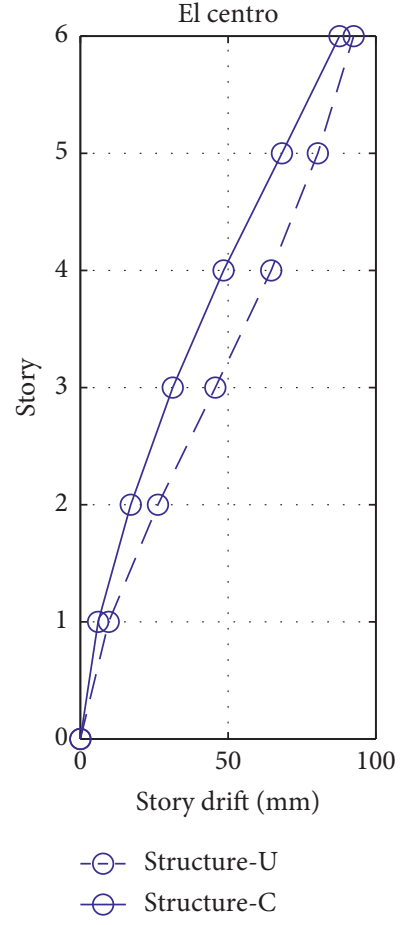

(a)

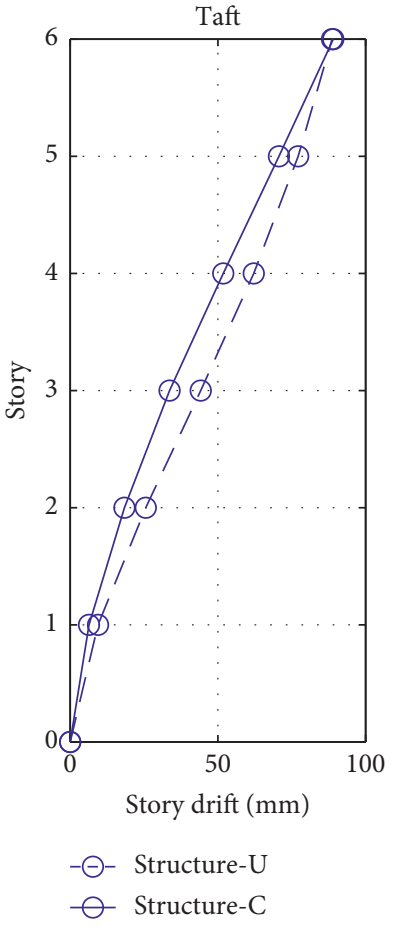

(b)

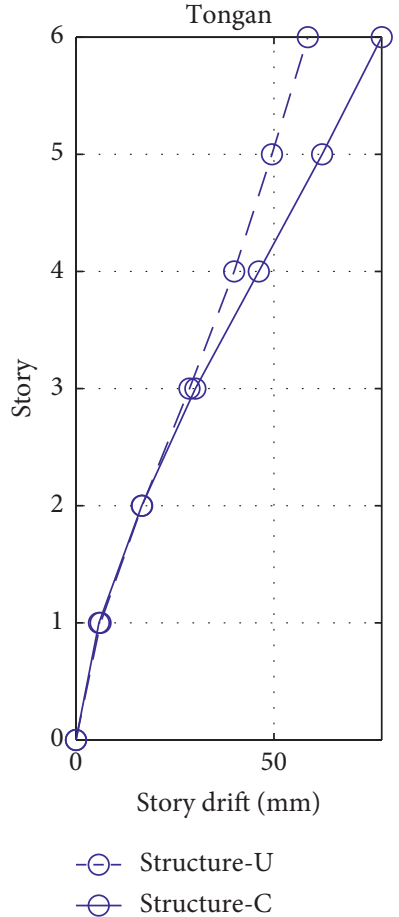

(c)

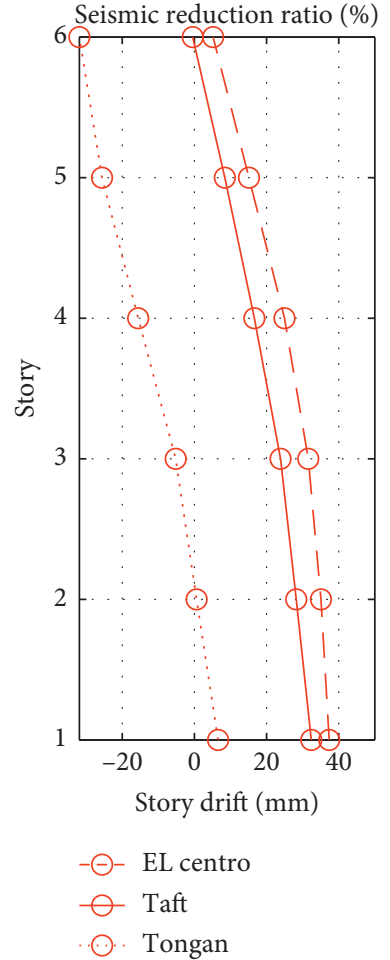

(d)

FIgURE 17: Story drift and its seismic reduction ratio. 
TABLE 2: Story shear seismic reduction ratio (\%).

\begin{tabular}{|c|c|c|c|c|c|c|}
\hline & Story 1 & Story 2 & Story 3 & Story 4 & Story 5 & Story 6 \\
\hline EL Centro & 38.9 & 38.2 & 40.4 & 37.3 & 30 & 37.5 \\
\hline Taft & 41.7 & 38.5 & 39.1 & 31.9 & 23.5 & 28 \\
\hline Tongan & 36.8 & 34.3 & 34.2 & 34.4 & 30.7 & 33.1 \\
\hline Average & \multicolumn{4}{|c|}{ Stories $1-6,34.9$} & Stories 4-6, & \\
\hline
\end{tabular}

TABLE 3: Story drift seismic reduction ratio (\%).

\begin{tabular}{|c|c|c|c|c|c|c|}
\hline & Story 1 & Story 2 & Story 3 & Story 4 & Story 5 & Story 6 \\
\hline EL Centro & 37.4 & 35.1 & 31.6 & 25 & 15.1 & 5.19 \\
\hline Taft & 32.4 & 28.2 & 23.9 & 16.6 & 8.43 & -0.47 \\
\hline Tongan & 6.56 & 0.6 & -5.2 & -15.6 & -25.6 & -31.9 \\
\hline Average & \multicolumn{4}{|c|}{ Stories $1-6,10.4$} & Stories 4-6, & \\
\hline
\end{tabular}

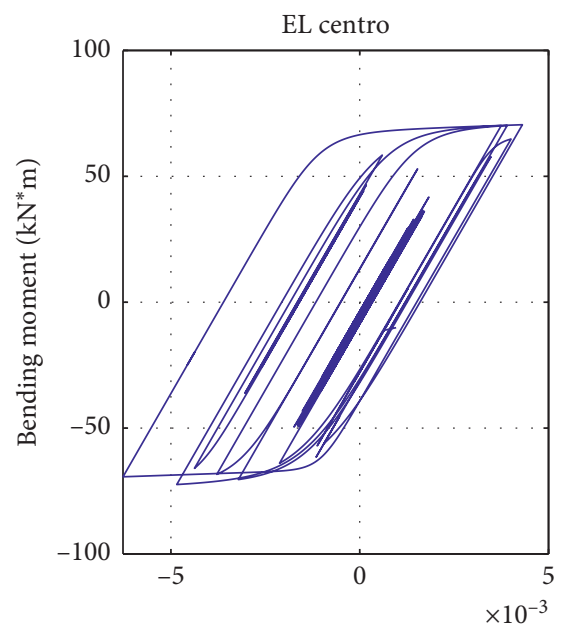

(a)

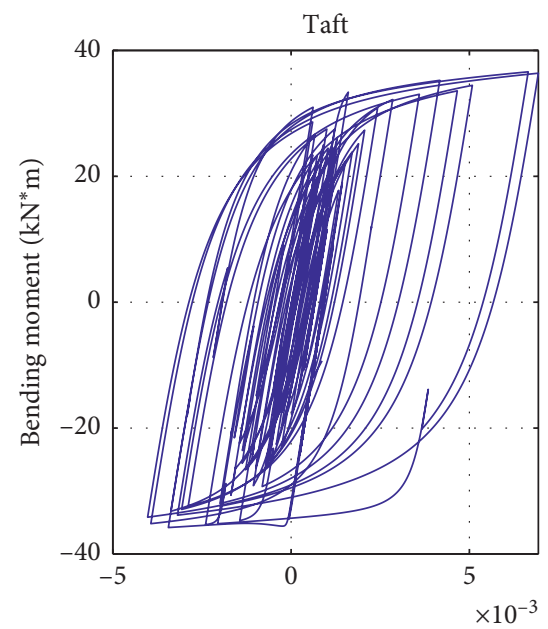

(b)

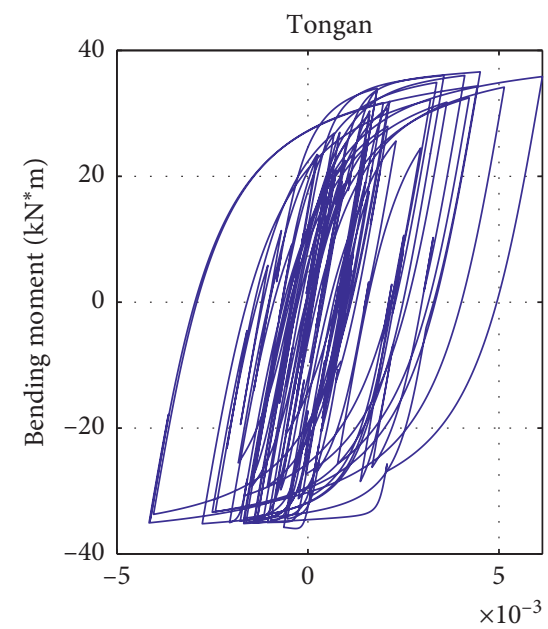

(c)

FIGURE 18: Hysteretic energy dissipation of damper in bending direction.

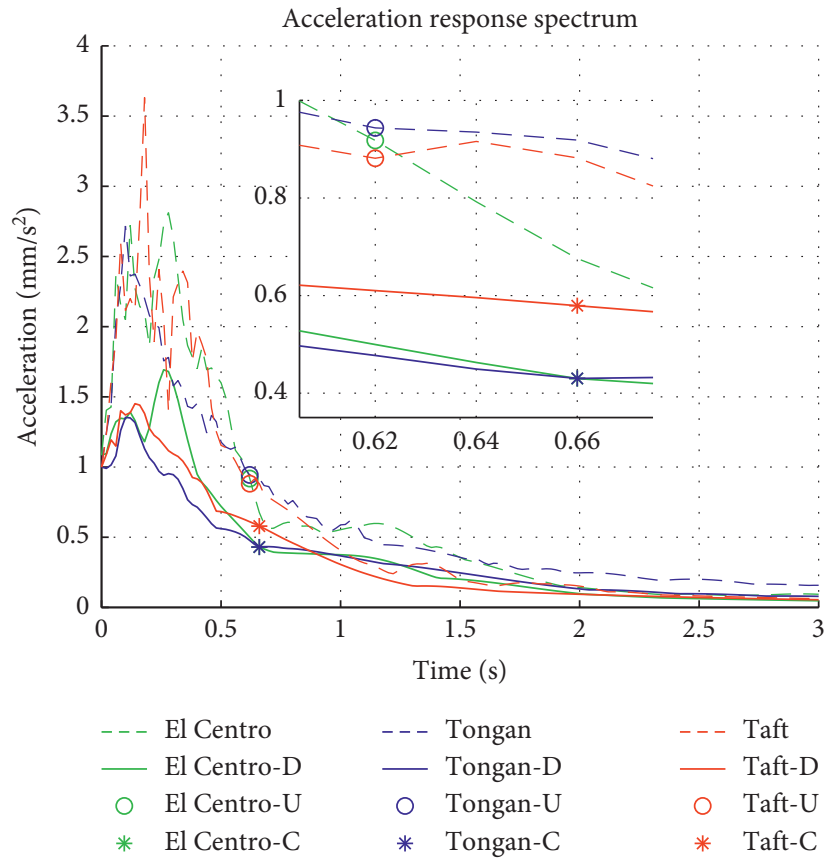

Figure 19: Pseudoacceleration response spectrum. 


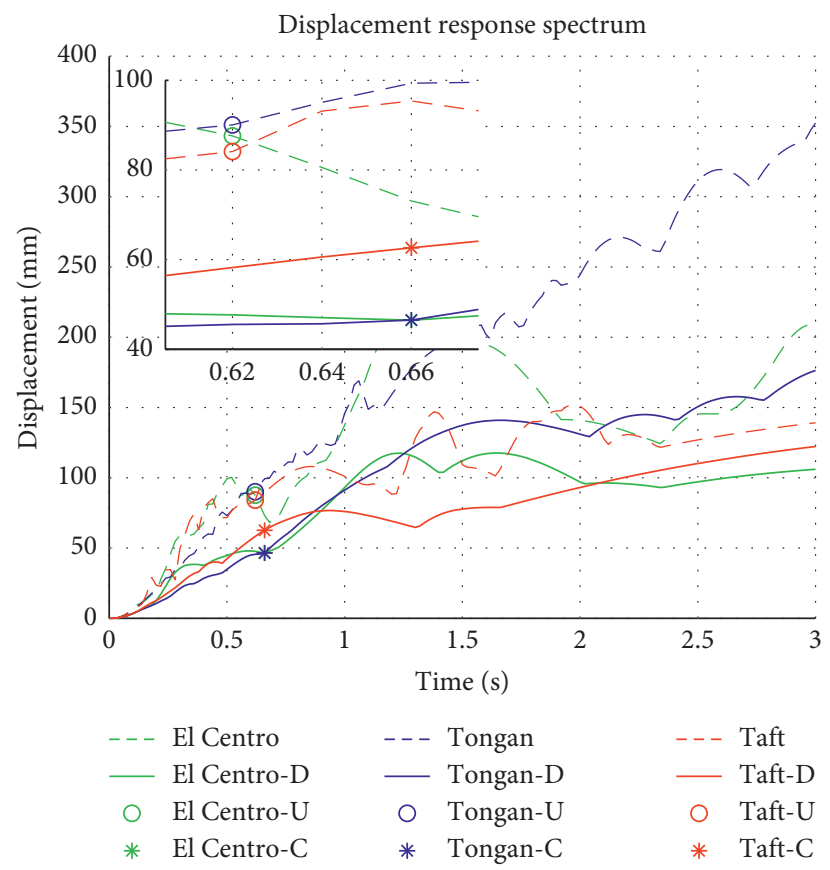

FIgURE 20: Displacement response spectrum.

caused by the deformation of the damper itself, the main components of the structure do not produce large deformation, or even intact. Therefore, in the formulation of design standards, it is recommended that the restrictions for displacement limits can be reduced, and specific seismic restriction standard can be even furtherly relaxed if certain conditions can be assured. For example, the Chinese "Code for Seismic Design of Buildings" [18] limits the elastoplastic interlayer displacement angle of reinforced concrete structures to $1 / 50$, which can be increased to $1 / 30$ under appropriate circumstances.

(3) Reasonable damper selection can obtain a better vibration control effect. Changes in the initial bending stiffness, yield bending moment, initial shear stiffness, yield force, and other parameters of the damper can affect the seismic response of the structure. Different parameters have different degrees of influence on seismic response, and some even have opposite effects. It is necessary to use performance curves or other methods for further parameter analysis.

(4) Optimization for the layout of the dampers: For example, using genetic algorithms to perform iterative calculations of different layouts [19] can enhance the shock absorption effect, or control the cost of the building while keeping the current shock absorption effect [20].

5.3. Design Result. With the example of this paper, combined with the above design suggestions, the deepening design is carried out. In the bending direction, within a certain range, the structural performance curve is illustrated in Figure 21. It shows the influence of the change in the yield

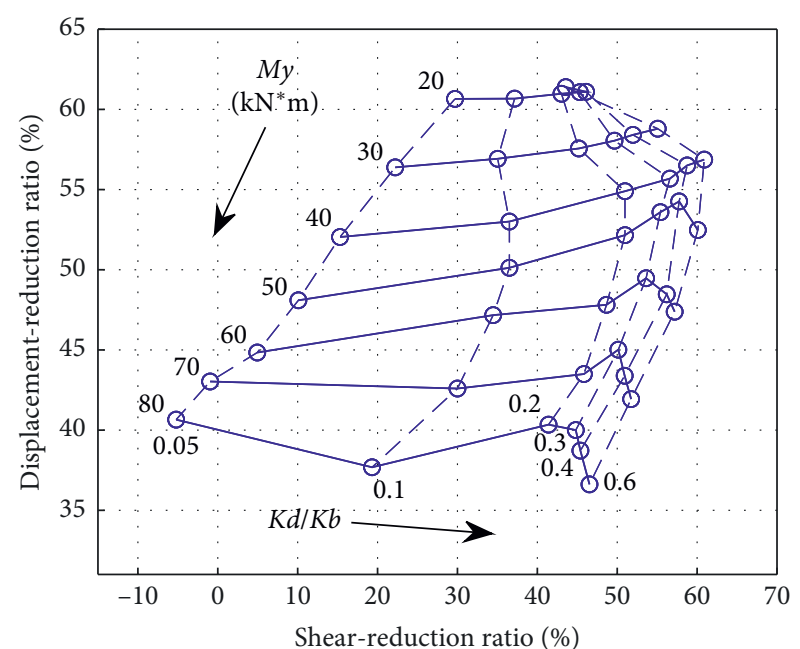

FIgURE 21: Curve of seismic reduction performance affected by bending direction parameters.

bending moment and the initial bending stiffness of the damper on the shear force seismic reduction ratio and the displacement seismic reduction ratio of the structural bottom layer.

$M y$ is the yielding bending moment; $K d / K b$ is the ratio of the initial bending stiffness of the damper to the bending stiffness of the frame beam. The solid line represents the influence of the initial bending stiffness on the seismic reduction rate under a constant yield bending moment, and the dashed line indicates the effect of the yield bending moment on the seismic reduction rate under a constant stiffness ratio. It can be seen from Figure 21 that, under the same bending moment, the seismic reduction rate of the shear force increases with the increase of the stiffness ratio. 

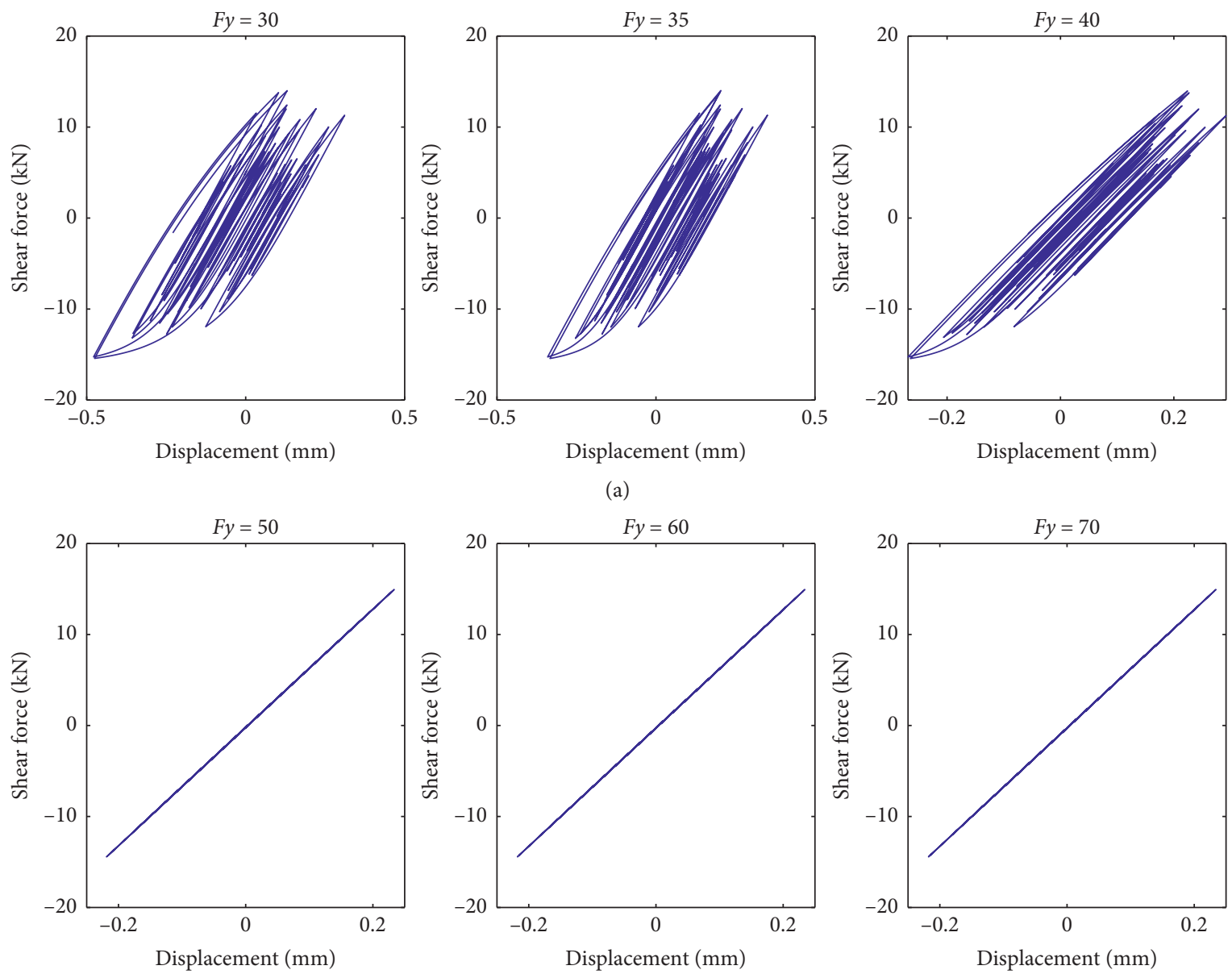

(b)

Figure 22: Hysteresis in shear direction $(K d / K b=0.2)$.
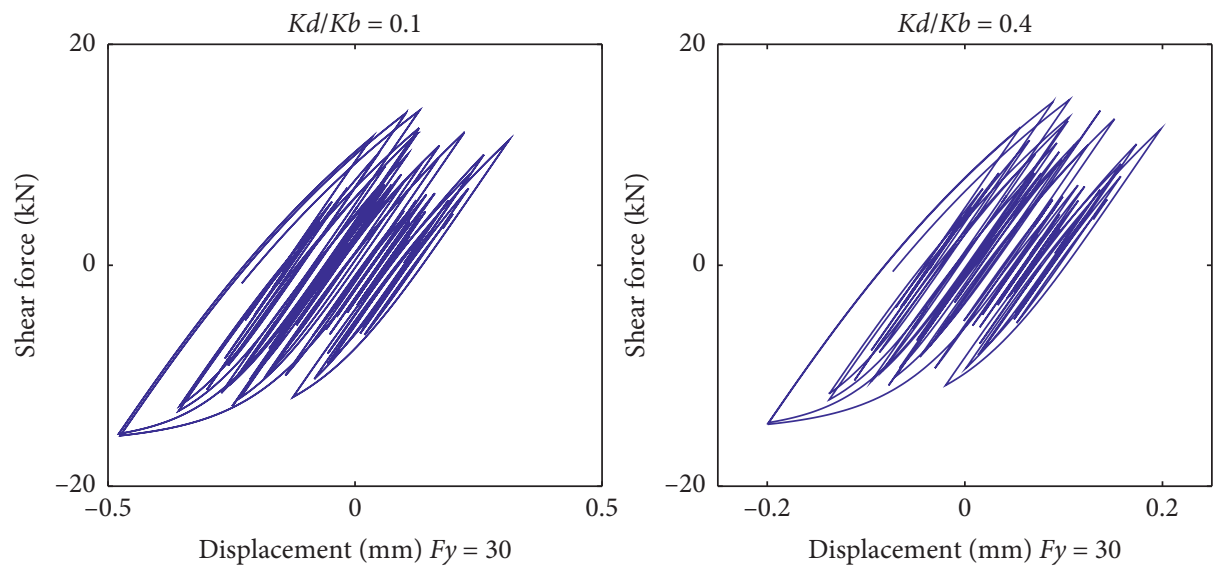

(a)

Figure 23: Continued. 

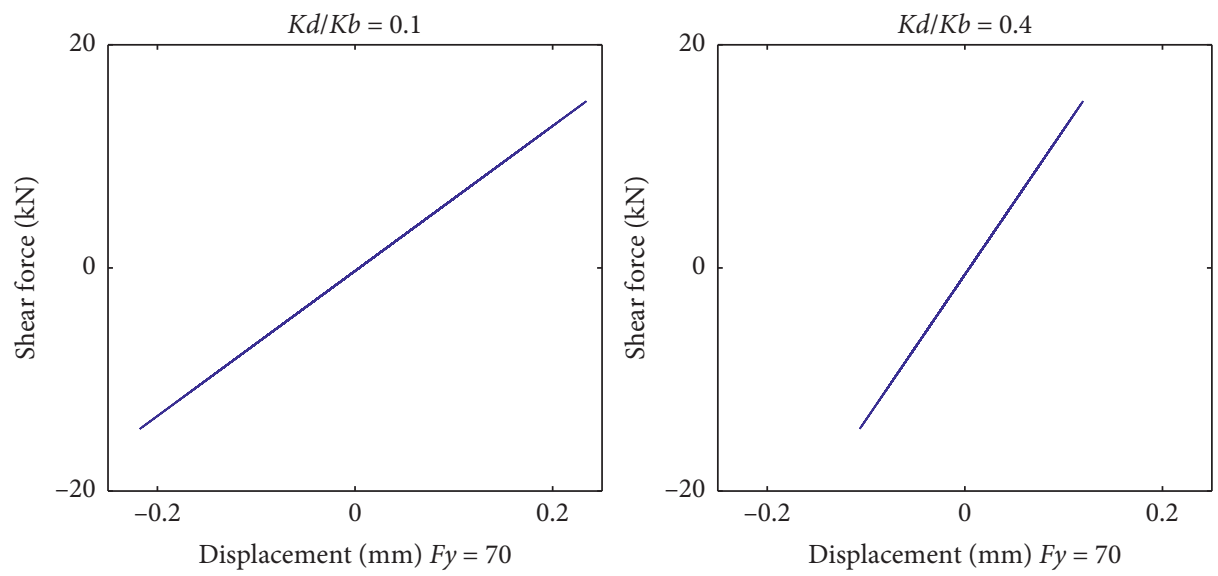

(b)

FIGURE 23: Hysteresis in shear direction $(F y=30 \mathrm{kN} / F y=70 \mathrm{kN})$.

When the stiffness is relatively small, this increase is significant, and this increase is slower when the stiffness is relatively large; therefore, the stiffness ratio in the range of 0.05 to 0.2 can be regarded as the sensitive area of shear force damping and the range greater than 0.2 is the nonsensitive area. When the stiffness ratio is greater than 0.2 , the change of the damper stiffness did not significantly affect the shear damping rate of the structure, but excessive stiffness will cause the reduction in the seismic reduction rate of the displacement. When the stiffness ratio was 0.05 and the yield bending moment was $80 \mathrm{kN} \bullet \mathrm{m}$ and $70 \mathrm{kN} \bullet \mathrm{m}$, the negative seismic reduction rate of shear force appears. Under the same stiffness ratio, the seismic reduction rate of the displacement significantly increases with the increase of the yield bending moment of the damper, while the shear damping rate changes little. From the seismic performance curve in the bending direction of the bottom layer, it can be seen that the optimal displacement and shear damping can be achieved when the yield bending moment is about $30-40 \mathrm{kN} \bullet \mathrm{m}$ and the initial bending stiffness ratio is about 0.2-0.6 effect. The optimal design range of the damper parameters for other floors can also be obtained using the same analysis method.

In the shear direction, the influence of the yield force and the change of the initial stiffness on the energy consumption of the damper is shown in Figures 22 and 23.

Both the yield force and the initial shear stiffness need to be designed within a certain range to make the damper consume energy. When the shear stiffness is the same, as the yield force increases, the hysteresis loop gradually decreases, even into a straight line. However, under the same yield force, the shear stiffness has little effect on the shear energy dissipation.

From the analysis of the design results of this case, it can be seen that the seismic reduction effect of the slotted energy dissipation joint structure is greatly influenced by the parameters of the bending direction, but the energy dissipation capacity of the damper is more sensitive to the shear direction parameters. Through reasonable design, an optimized damping effect can be achieved.

\section{Conclusions}

A new slotted mild steel damper was proposed in this study, which is applicable for the prefabricated structure to form as a beam-column energy dissipating joint. Based on the parameterized simulation of the slotted energy dissipating joint, the dynamic performance and seismic reduction mechanism of the controlled structures were analyzed. The conclusions are as follows:

(1) The yield mechanism of the frame indicates that the energy dissipation of the slotted damper effectively protected the main structure. Also, the damper has shown that it had good energy dissipation. The energy dissipation mainly occurred on the flange of the variable section. The beam-ribbed web ensured the required bearing capacity and rigidity, and the connection was reliable [21].

(2) The slotted energy dissipating joint can be simulated in OpenSees using the Steel02 Material model and the twoNodeLink element. This parameterized simulation is critical in analyzing the structure of the slotted joints.

(3) The structure with the slotted energy dissipating joint can reduce the seismic response. Compared to the uncontrolled structure, the controlled structure had a longer period and decreased the top story acceleration. Also, the shear-dependent seismic reduction ratio of the controlled structure was about $35 \%$, and the drift-dependent seismic reduction was about $10 \%$. The bottom story had a better seismic reduction effect than the top story, and the damper had good energy dissipation in the bending direction.

(4) Through the analysis of acceleration response spectrum and displacement response spectrum, design suggestions for energy-consuming node structures are put forward. On this basis, the design can be deepened to achieve better shock absorption effect. 


\section{Data Availability}

The data used to support the findings of this study are included within the article or can be obtained via e-mail from the corresponding author.

\section{Conflicts of Interest}

The authors declare that they have no conflicts of interest regarding the publication of this paper.

\section{Acknowledgments}

This paper was supported by the National Natural Science Foundation of China (Grant no. 51678158), Scientific Research Project Foundation for Young and Middle-Aged Teachers in Fujian Province (Grant no. JAT170615), and Research Talent Training Project of Fujian Jiangxia University (Grant no. 20kx17xz04). In addition, the members of the research group subject provided help in the amendments; the authors appreciate them for their help.

\section{References}

[1] H. H. Korkmaz and T. Tankut, "Performance of a precast concrete beam-to-beam connection subject to reversed cyclic loading," Engineering Structures, vol. 27, no. 9, pp. 1392-1407, 2005.

[2] B. Zoubek, T. Isakovic, Y. Fahjan, and M. Fischinger, "Cyclic failure analysis of the beam-to-column dowel connections in precast industrial buildings," Engineering Structures, vol. 52, pp. 179-191, 2013.

[3] J. Lee and J. Kim, "Development of box-shaped steel slit dampers for seismic retrofit of building structures," Engineering Structures, vol. 150, pp. 934-946, 2017.

[4] L. Y. Xu, Y. Q. Lin, and Y. X. Wu, "Seismic response analysis of a first-story isolated reinforced concrete frame building with independent columns," Advances in Structural Engineering, vol. 23, no. 14, pp. 3140-3152, 2020.

[5] G. Wu and D. C. Feng, "Research progress on fundamental performance of precast concrete frame beam-to-column connections," Journal of Building Structures, vol. 39, no. 2, pp. 1-16, 2018.

[6] C.-H. Lee, S.-H. Lho, D.-H. Kim, J. Oh, and Y. K. Ju, "Hourglass-shaped strip damper subjected to monotonic and cyclic loadings," Engineering Structures, vol. 119, pp. 122-134, 2016.

[7] P. Martinelli and M. G. Mulas, "An innovative passive control technique for industrial precast frames," Engineering Structures, vol. 32, no. 4, pp. 1123-1132, 2010.

[8] G. W. Rodgers, K. M. Solberg, J. B. Mander, J. G. Chase, B. A. Bradley, and R. P. Dhakal, "High-force-to-volume seismic dissipators embedded in a jointed precast concrete frame," Journal of Structural Engineering, vol. 138, no. 3, pp. 375-386, 2012.

[9] C. $\mathrm{Wu}, \mathrm{X} . \mathrm{Xu}$, and Y. Zhou, "Restoring force model and design method of sector lead viscoelastic damper," Journal of Vibration and Shock, vol. 34, no. 12, pp. 18-22, 2015.

[10] Y. Dong, Z. Xu, and T. Ge, "Seismic performance of RC frame structures with high-energy dissipation haunch braces of viscoelastic dampers," Journal of Southeast University (Natural Science Edition), vol. 48, no. 4, pp. 662-670, 2017.
[11] R. W. K. Chan and F. Albermani, "Experimental study of steel slit damper for passive energy dissipation," Engineering Structures, vol. 30, pp. 1058-1066, 2007.

[12] H. Saffari, A. A. Hedayat, and M. P. Nejad, "Post-Northridge connections with slit dampers to enhance strength and ductility," Journal of Constructional Steel Research, vol. 80, pp. 138-152, 2013.

[13] A. A. Hedayat, "Prediction of the force displacement capacity boundary of an unbuckled steel slit damper," Journal of Constructional Steel Research, vol. 114, pp. 30-50, 2015.

[14] C.-H. Lee, Y. K. Ju, J.-K. Min, S.-H. Lho, and S.-D. Kim, "Nonuniform steel strip dampers subjected to cyclic loadings," Engineering Structures, vol. 99, pp. 192-204, 2015.

[15] H. A. Amiri, E. P. Najafabadi, and H. E. Estekanchi, "Experimental and analytical study of block slit damper," Journal of Constructional Steel Research, vol. 141, pp. 167-178, 2018.

[16] M. Wang, F. X. Qian, and W. G. Yang, "Comparison study on constitutive relationship of low yeild point steels, Q345B steels and Q460D steels," Engineering Mechanics, vol. 34, no. 2, pp. 60-68, 2017.

[17] F. C. Filippou, E. P. Popov, and V. V. Bertero, Effects of Bond Deterioration on Hysteretic Behavior of Reinforced Concrete joints, Earthquake Engineering Research Center, Oakland, $\mathrm{Cl}$, USA, 1983.

[18] Architecture \& Building Press, Code for Seismic Design of Buidings: GB500011-2010, Architecture \& Building Press, Beijing, China, 2016.

[19] J. T. Qu, H. N. Li, and G. Li, "Optimal placement of displacement-based energy dissipative devices for passive response control," Engineering Mechanics, vol. 26, no. 1, pp. 43-48, 2009.

[20] J. Kim and H. Shin, "Seismic loss assessment of a structure retrofitted with slit-friction hybrid dampers," Engineering Structures, vol. 130, no. 2, pp. 336-350, 2017.

[21] A. Banisheikholeslami, F. Behnamfar, and M. Ghandil, "A beam-to-column connection with visco-elastic and hysteretic dampers for seismic damage control," Journal of Constructional Steel Research, vol. 117, pp. 185-195, 2016. 